\title{
Normalisation in Mental Handicap-Acceptance without Questions?
}

ANNE BouCherat, Senior Registrar, Section of Mental Handicap, Division of Psychiatry, United Dental and Medical Schools, Guy's Hospital, London, SEl

When searching for a definition of mental handicap, I came across the following:

"Handicap is something imposed on a disability to make it more limiting than it need necessarily be." (Shearer, quoted in O. Russell, 1985). ${ }^{1}$

I had been thinking in terms of a definition which would take into account the assumed Gaussian distribution of 'intelligence' and the consequent arbitrariness of any cutoff point between 'normal' and 'mentally subnormal': which would also take into account social criteria "since a distinction must be made between people who can lead a normal or near-normal life and those who cannot." 2

I liked Shearer's definition, though, because I agree that mental handicap should be defined as a state which is only partly intrinsic to the mentally handicapped person and which exists also as a function of the handicapped person's relationship with the rest of us.

Mental handicap is generally seen as a condition to be prevented and regretted: detection of a foetus that may develop into a mentally handicapped individual is grounds for termination of pregnancy; the birth of a mentally handicapped child is regarded as such bad news for the parents that they are expected to go through a process akin to grieving. So I remember being extremely startled when, in Ireland as a medical student, I heard a priest say on television that the mentally handicapped are the most valuable people in society.

My own view of mental handicap as a highly undesirable condition partly explains the dismay I felt when I learnt that I was to spend six months working with mentally handicapped adults. I started the job with some knowledge of heritable syndromes and with preconceptions about the patients' intrinsic defects and disabilities; but in fact, what was more immediately apparent and distressing was the low self-esteem of many of my patients, with their head-down, eyes-averted stance and apologetic utterances. I imagined that they had experienced rejection, failure and mockery as 'backward' children and adults and that submissiveness was the least disadvantageous adaptation to this. I imagined also that they had internalised society's low valuation of people who cannot read and who look odd. All this, for some, was compounded by the depersonalising, demoralising effect of institutional life.

I was surprised to find myself becoming so uncomfortably aware of the existence of an inner world for mentally handicapped people, and I was also surprised to meet staff who talked in an embattled way about how they planned to revolutionise existing social values in the interests of their mentally handicapped patients or clients. These staff, I discovered, were proponents of the Philosophy of Normalisation-one of them told me that her belief in normalisation was what made her work endurable.

The philosophy of normalisation entails far more than bringing about the sort of humane and de-institutionalising changes that are recommended in the Government paper, Better Services for the Mentally Handicapped -although it may have helped to inspire them. The recommendations include: enabling mentally handicapped people to live in as 'homelike' a place as possible; avoiding segregating them from the 'general life of the community'; and attempting to provide each person with appropriate stimulation and purposeful occupation. ${ }^{3}$

The philosophy of normalisation aims more radically to change the lot of mentally handicapped people, to acknowledge and treat them "as full and valued citizens". It seems to arise from principles of human rights and its starting point is to view the mentally handicapped as people with intrinsic value who have been devalued by society: devalued people are now "massively and persistently the objects of rejection and destruction." 4 The argument is that changing the ways in which mentally handicapped people are helped or served will bring about a change in social attitudes, such that mentally handicapped people will no longer be segregated and devalued: segregation in itself tends to lead to further devaluation.

Wolfensberger, one of the originators of the philosophy, defines normalisation briefly as:

"using culturally valued means in order to enable people to lead culturally valued lives."

Normalisation literature contains a great deal of discussion on what is really meant by 'culturally valued', and on how the 'cultural value' of a service can be assessed. It suggests that a form of positive discrimination should be used when making decisions about providing services, and it calls, in its special language, for "options that either fall within the normative range, or even better, fall within the supranormative valued end of the continuum of culturally valued options." 4 An example of providing "supranormative" culturally valued means of help might be providing a taxi for a person to travel from home to the sheltered employment every day, rather than a bus with "Services for the Handicapped" painted on the side.

Wolfensberger's argument-that changing the means by which handicapped people are helped will affect their value 
in the eyes of non-handicapped people, and that this, by a sort of positive feedback loop, will further enhance the services they receive-pivots around the personal relationships that are formed between the handicapped and the non-handicapped:

"Strategically, there simply does not exist a better long-term safeguard for the welfare of retarded individuals than a large number of intimate and positive one-to-one relationships between them and other citizens ... Valued people are virtually never segregated from society against their will." 4

The "intimate and positive one-to-one relationships" are thus crucial if we are to stop damaging and devaluing mentally handicapped people. In my own work, facing my reluctance to form such relationships with my mentally handicapped patients was constantly unsettling and uncomfortable.

In the ordinary world, practical impediments in the way of such "intimate, positive, one-to-one" relationships being formed between handicapped and non-handicapped people are many and include, at the most obvious, lack of opportunity to meet each other and lack of common experience. These may be being tackled by enabling mentally handicapped people to live in the community rather than in hospital. Most other impediments to forming such relationships can be embraced by the general term, 'social stigma'. Goffman, in his detailed study of stigma, highlights the meeting between a 'normal' and a 'stigmatised' person as "one of the primal scenes of sociology: for ... these moments will be ones where the causes and effects of stigma are confronted by both sides." 5

Amongst other 'causes and effects', each party will bring to this 'primal scene' fears of the other's differentness, anxieties about their own vulnerability, and defences and behaviours to cope with these. In this encounter the mentally handicapped person may also have to deal with disabilities such as incontinence, impaired cognitive skills, a speech impediment: the non-handicapped person may have to deal with uncertainty about whether the handicapped person will conform to expected conventions-"what might he do next?"- and with the knowledge that social stigma tends to contaminate those who associate with the stigmatised - "I don't want to be seen talking to him."

I feel that at all levels there is a great gulf to be crossed in this encounter between a mentally handicapped person and a person who is not mentally handicapped: arguably, this is an even more tricky crossing than that needed in relationships with people who are 'different' or 'stigmatised' for any other reason. Goffman recognises that the social standing of mentally handicapped people is very low indeed, and gives an example of inmates of an institution for the mentally handicapped trying to pass themselves off as patients from a hospital for mentally ill people, seeing even that as being less shameful than their own position. In our competitive world, where the intellect is so highly valued, we have correspondingly very deep and secret feelings about our own position on a scale of intelligence. Alongside our deep-seated sexual, class and racial prejudices, our anticipatory opinions about the intelligence of others play a part in all our relationships-not least in multi-disciplinary teams.

It does not seem likely to me that outward changes alone-changes, for example, in where mentally handicapped people live, what sort of transport they use and in what they wear-will do much to alter other people's partlyconscious feelings about those who are less intelligent than themselves. It seemed odd that, although a stated aim of normalisation is to "help our society become more accepting of people's differences", 6 none of the people who talked to me about normalisation, not even those who were most passionately devoted to putting it into practice, and also none of the introductory literature I read, said anything about the inner changes that need to occur before mentally handicapped and normal people accept one another in "intimate and positive, one-to-one relationships".

Indeed, one important criticism that has been made of the normalisation philosophy is that it fails to recognise the existence of people's internal worlds. Writing about normalisation (in this case with reference to the mentally ill but equally important where the mentally handicapped are concerned), Paul Clifford describes proponents of normalisation as tending to deny "the existence or the importance of feelings, states of mind that are not a direct product of the environment." 7 Goffman, on the other hand, whose book Stigma is based on a large number of accounts of personal experiences, notes the importance of the internal changes that may happen when "acceptance" occurs between a normal and stigmatised person. The normal person becomes someone "before whom the individual with a fault need feel no shame nor exert self-control, knowing that despite his failing he will be seen as an ordinary other." To reach this, he or she "may first have to pass through a heart-changing personal experience." "s

Joan Bicknell, in her paper on the psychopathology of handicap, names stages on the route to "acceptance"-in this case, acceptance of a mentally handicapped child by his or her parents. Here too there is disability which entails social disadvantage and guilt felt by the parents who have produced a handicapped child; the parents' task in coming to terms with these things is comparable with the process of forming an accepting friendship with a stigmatised person. She writes, "Bargaining gives way to acceptance, when the pain subsides and love takes over, and reality can be grasped." 8

Both Goffman and Bicknell thus appear to agree that if respectful and accepting relationships between mentally handicapped and non-mentally handicapped people are to be formed, then profound changes on the emotional or even spiritual level of experience must take place within the people concerned. It seemed to me initially that, in normalisation theory, this "heart-changing personal experience" was unrecognised, even though it must be a prerequisite for the very relationships which promote and maintain the changes in social values for which normalisation aims. Not recognising this step in the process would mean that the proponents of normalisation were not giving themselves access to all the understanding of relationships and intra- 
psychic processes that has been gained in the field of psychoanalysis; also they would not be interested in theological views of the changes of mind, heart and direction called 'metanoia' or 'repentance'.

However, the more I read about normalisation, the more I began to feel that the language of social administration was being used to disguise an evangelical message. I thought that, without ever saying so, Wolfensberger is well aware of the emotional changes he wants people to undergo. The philosophy of normalisation seems to be setting out a way of preparing people to undergo an experience akin to religious conversion-the "heart-changing personal experience" that Goffman describes.

The language of the pulpit is sometimes used, and this is less incongruous than it seems once you realise that the aim is conversion. For example, in defending normalisation against critics and heretics, Wolfensberger writes, "There is nothing good in the world that will not come under attackand I mean under hateful attempts to destroy what is good so that evil will prevail." 4 The swings between such declarations and polysyllabic sociological language- as, for example, "supranormative valued end of the continuum"may reflect an ambivalence about the emotional and spiritual concomitants of normalisation: Wolfensberger frequently implies their existence but avoids examining them.

Paul Clifford makes a direct comparison between advocates of normalisation and members of 'born again' religious sects: he points to their "similar combination of dogmatism, naiveté about human nature and loudly expressed concern for the needy." 7 Renshaw, ${ }^{9}$ in her description of a 'PASS' workshop (the intensive teaching method used to propagate the ideas of normalisation), makes mention of intense group pressure, special language and withdrawal from the outside world as features of the experience. To this I can add, from conversations with people who have attended these courses: discouragement of doubt: talking to the point of exhaustion; and confessions of 'wrong' attitudes. I think that this list covers many of the techniques used for inducing sudden conversion.

Ryan, in The Politics of Mental Handicap, ${ }^{10}$ points out that there are ways of arriving at "acceptance" of mentally handicapped people which do not necessitate sudden conversion: however, a precondition is that the "normal" people must start out with a set of values-often Christianvery different from those which are generally socially accepted. She also believes that a degree of isolation from society may be needed if people are to sustain these beliefs. If those conditions are fulfilled, then mentally handicapped people can be accepted as "an inspiration to others, an indictment of the inhuman values of the rest of the world, a reminder of buried and more vulnerable parts of ourselves". She adds, "These perceptions are of decisive importance in allowing us to value them, in finding some common humanity." It is as though she-like the Irish priest-sees the social role of mentally handicapped people as being that very old one of 'holy fool', who helps 'normal' people to become humbler and more self-aware. "In their poverty they are more simple and loving and thus they reveal to us the poverty of our riches." (Founder of L'Arche Community, quoted by Ryan, 1980).

I do not wish to suggest that an accepting friendship between a mentally handicapped person and an ordinary, non-religious, non 'normalised' person is an impossibility: I am sure that many such friendships exist. However, because of the deep-seated and confusing nature of the feelings on which our treatment of people with a mental handicap is based, even a large number of "heart-changing personal experiences" would not necessarily generalise to a change of heart on the part of our meritocratic, secular society as a whole.

It seems to me that the only sort of social ideology in which widespread respectful acceptance of mentally handicapped people can occur-that is to say, in which the ideals of normalisation can be realised-is one where humility is prized and there is agreement not to gain social advantage by using intellectual skills. Normalisation demands that we turn our existing social values upside-down. Wolfensberger likens normalisation to "radical Christianity ... idealistic agrarianism ... even idealised socialism." 4 Behind the humane and government-sanctioned practices of moving mentally handicapped people out of hospital and enabling them to have a little more control over their destiny, there lies the principle of normalisation which is as revolutionary as any of these three ideologies and as monumentally ambitious.

REFERENCES

${ }^{1}$ Russell, O. (1985) Mental Handicap. Edinburgh: Churchill Livingstone.

${ }^{2}$ Gelder, M., GATH, D. \& MAYou, R. (1983) Oxford Textbook of Psychiatry. Oxford University Press.

${ }^{3}$ Department of Health \& Social Securuty (1971) Better Services for the Mentally Handicapped. London: HMSO.

'WOLFENSBERGER, W. (1980) Chapter 4 in Normalization, Social Integration and Community Services (eds. Robert J. Flynn et a). Baltimore: University Park Press.

${ }^{5}$ Gofrman, E. (1963) Stigma. London: Penguin.

${ }^{6}$ Tyne, A. (1981) Staffing and Supporting a Residential Service. Campaign for Mentally Handicapped People, 16 Fitzroy Square, London WIP 5QH.

'Clifford, O. (1986) Why I haven't joined the normies: Some doubts about normalization. SE Thames Region Rehabilitation Interest Group Newsletter, No. 5.

${ }^{8}$ BickNeLl, J. (1983) The psychopathology of handicap. British Journal of Medical Psychology, 56, 167-178.

${ }^{9}$ Renshaw, J. (1986) Passing understanding. Community Care, 17 July 1986, 19-21.

${ }^{10}$ Ryan, J. (1980) The Politics of Mental Handicap. London: Penguin. 